\title{
Higher degree research by numbers: beyond the critiques of neo-liberalism
}

\author{
Liam Grealy and Timothy Laurie
}

\section{Introduction}

Like the category of obscenity in art, neo-liberalism seems to obey a maxim that ensures its regular circulation within university folklore: we know it when we see it. We know something neo-liberal is happening when generous colleagues fail to have their contracts renewed because they do not meet obscure metrics for research performance derived from Key Performance Indicators (KPIs). We know neoliberalism has taken hold when, rather than pursuing their interests or talents, students make course choices based on perceived benefits for future employment incomes to repay higher tuition fees resulting from sector-wide marketization and deregulation. We know that we belong to neo-liberal institutions when the carefully formed languages of specialist disciplines are replaced by the languages of management, such that a research project acquires value only through its outputs, its impacts, its scalability, its 'innovations', or its potential to produce further growth. And yet, we do not always know what a unifying concept such as 'neoliberalism' adds to all of this knowing.

Many contemporary commentaries on neo-liberalism could be classified as what Eve Sedgwick, following Silvan Tomkins, calls 'strong theories'. Strong theories claim to be 'capable of accounting for a wide spectrum of phenomena which appear to be very remote, one from the other, and from a common source' (Tomkins, quoted in Sedgwick, 2003, p. 134). For example, Marxist political economists have been accused of being overly 'functionalist' in their accounts of neo-liberalism, by attributing multiple transformations to a single causal factor - the struggle between capital and labour (Flew, 2014, p. 58). Calling Marxism a 'strong theory' does not mean saying that it is false, only that its most common articulations involve moving from an unstable multiplicity of effects to a more stable continuity of causes. But cultural accounts of neo-liberalism can also contain similarly 'strong' impulses. For example, competitive reality television programmes or self-help books have been described as neo-liberal because they participate in the common logic of individual self-determination, even if competitive games and popular psychology have entirely different cultural origins. Elsewhere, neo-liberalism has been identified in the ideology of 'linear time' subtending European colonialism, thereby linking the critique of neo-liberalism to a strong theory of global- and post-coloniality (Shahjahan, 2015, p. 491). These strong theories present contrasting narratives about the historical duration and geographical scope of neo-liberalism, but they do share a commitment to distinguishing between neo-liberalism as a unitary cause and social interactions as derivative effects. This raises the following questions: when we use neo-liberal as a modifier - neo-liberal society, neo-liberal university, neo-liberal subject - do we mean that these phenomena would not exist without neoliberalism? Or, do we mean that neo-liberalism has merely modified already existing phenomena? 
This article argues that the strong theorization of neo-liberalism does not provide an adequate frame for understanding the local circumstances attending one of its most recognizable components: measurement. We do so by examining contemporary pressures on, and techniques employed in, higher degree research (HDR) programmes. It is an educational truism that the most exciting learning experiences are hard to measure, and that the experience of being measured is hardly exciting. The experience of completing a PhD dissertation brings this issue into sharp relief, as graduates frequently encounter a mismatch between the intellectual and emotional work required to complete a thesis, and the performance indicators used to sort applicants for academic positions, which may only have a tangential relationship to the substantive achievements of the thesis. But singular learning experiences are difficult to incorporate into staff meetings, curriculum reviews or institution-wide policy initiatives. Measurement can therefore arrive as a way of 'getting things done' in finite decision-making environments, even when this involves drawing upon impoverished representations of lived experiences. Rather than understanding measurement practices according to the criteria of naturalism that would seek to represent the world 'as it is', we understand such practices as material signs with varying degrees of embeddedness in social and institutional worlds. In this context, the article argues that many critiques of neo-liberalism do not sufficiently advance alternative ways to think about the purposes of higher education, and that correspondingly, 'neo-liberalization' does not exhaustively explain the issues attending increased measurement and surveillance practices in HDR environments. We therefore want to focus on the worlds that measurements bring into being, and on the criticisms made of these worlds in contemporary sociological research on higher education.

Measurement is examined here from three distinct viewpoints. Firstly, we revisit contemporary studies of the neo-liberal university, and consider the high premium placed on measurement as the privileged technology of institutional progress. The article suggests that metrics often become mobile sites of powerful collective investment, and that even those sceptical about the purposes of metrics can come to care about and desire certain numbers. Secondly, we focus on specific concerns raised around measurement regarding HDR. Postgraduate environments are considered by many to be the final bastions of passionate intellectual inquiry protected from the continuous measurements that attend most undergraduate programmes. The incremental reframing of doctoral study in Australian universities as an outcomes-driven pursuit places heightened pressure on educators to clearly identify those features of long-term research projects that may have immeasurable outputs. Finally, as a gesture towards imagining alternative ways of thinking about learning outcomes, the article argues that pedagogical environments need to find ways to make HDR 'failures' - non-submissions, abandoned projects, flawed ideas - institutionally worthwhile and intellectually generative. It may be that measurement cultures are best inhabited by learning how to fail well.

\section{Measurement and higher education}

The relationship between quality and quantity has widespread significance for organizations interested in measuring 'quality' practices and objects (see Anderson, 2006). In simple terms, qualities are properties that allow one thing to be 
distinguished from another thing. For example, blue is a quality that can be distinguished from red. Some qualities have direct quantitative correlates (blue has a wavelength of 450-495 nanometres), but many concepts describe nonquantifiable qualities. For example, the musical notion of 'timbre' has been used to describe composite variables, where no single quantity - amplitude, pitch, resonance - is completely essential to the concept. By contrast, quantification presupposes exactness in the units quantified, and there is no quantity that does not require a fixed separation between qualities. However, numerical measurements can easily become unmoored from the experiential world of qualitative differences, producing differential numbers with no sensible referent. For example, the birth rate in Australia in 2012 was 1.93 children per Australian female, and although qualities are required to distinguish one birth from another, one cannot imagine 1.93 children. Furthermore, a changing annual birth rate may be detectable only across a large-scale population, and a national shift from 2.03 to 1.93 may go unnoticed within any particular community. Used in this way, measurement practices may risk alienating or disempowering those to whom they are applied, either because the objects being measured cease to be tangible in everyday experience (1.93 children), or because metrics may suffer from scaling effects, where extremely broad trends contain little explanatory power at a local level (2.03 to 1.93). The development of proxy indicators and probabilistic inferences (see Shachter, 1988) to measure large groups - students, workers, voters - can often produce measurements more useful for the governance of a population than for assisting the practices or improving the well-being of any particular individual within that population.

This opens onto the issue of the organizational structures that coordinate measurement practices. Within institutional settings, disagreements about the purposes, frequency and effects of measurement can reflect structural conflicts between various stakeholders in the production of quantitative data. Measurement practices simultaneously reflect and modify relationships between those who measure and those who are measured. In a variation of commodity fetishism, the aura of objectivity acquired by measurement practices can mask the social power relations between managers and the managed. This may also mean that key metrics come to be defined not by their utility to individual practitioners, but by their capacity to travel upwardly through an organizational administration. Numbers begin signifying more easily as reliable 'proof' once they circulate beyond an original 'circle of belief' - that is, those who actually produced the numbers (Kamuf, 2007, p. 257). Issues of this kind are regularly raised regarding the measurement of 'learning' and 'research' in the Australian tertiary sector, and such measurements have particular impacts on HDR students. We can only offer a sample here of the measurement practices that attend HDR programmes in Australian universities, but they are broadly indicative of wider trends.

Firstly, students are evaluated for entry into research programmes and eligibility for scholarships. For example, RMIT University's 'Model to determine merit-based selection' establishes a candidate's score based on their highest qualification (up to 55 percentage points), a school allocated score (up to 15), and either a combination of recent degree (20) and publications (10) or publications (10) and relevant 
professional experience (20) (RMIT, 2011, p. 1). In this formula, a Master's degree by research is equivalent to 20 years' relevant professional experience, and a refereed article in a scholarly journal is equivalent to an original creative work of international significance. Once enrolled, doctoral candidates are measured at regular intervals within their candidacy, often through discrete and ordinal indicators such as satisfactory, less than satisfactory, unsatisfactory. Although many doctoral candidates will not be able to pursue stable academic careers (see Mayhew, 2014), many will learn to recognize the KPIs used to measure academic performance, especially those that could shape future employment opportunities: publication outputs and the H-Index, student evaluation scores, 'impact' scores and so on. For the measurement of cohorts or populations, university administrations frequently mobilize recruitment rates, completion rates and post-doctoral employment rates. Differentiated metrics produce a logic of continuous improvement, where strong performance is not measured according to a fixed standard (60-70, 70-80), but is oriented instead towards infinite growth and expansion (e.g., $2 \%$ per annum). Finally, any metric whatsoever can be subsumed within a system of ordinal measurements, or rankings. Ordinal rankings for programmes, institutions, journals and publishers can have a significant impact on what Guy Roberts-Holmes (2015) calls 'data chains', with institutions modifying postgraduate recruitment practices to improve the rank attached to programmes, faculties or entire universities, and to reduce any penalties attached to HDR candidates who fail to complete (this is relevant for the distribution of Australian Postgraduate Award scholarships). Unlike interval variables, ordinal variables do not require any specification of the gap between each placement, such that trivial differences between individuals can acquire a heightened sense of symbolic meaning (see Bowman \& Bastedo, 2011, p. 441). Tacit logics of ranking may also shape the interpretation of data intended to be criteria-based. For example, the Excellence in Research for Australia (ERA) framework claims to evaluate programmes 'against national and international benchmarks', but the resulting numbers frequently circulate among potential postgraduate students as proxies for 'best' or 'worst' programme (on the ERA, see Redden, 2008).

Sociologists of higher education have amply shown that measurement practices across universities worldwide can produce distorted understandings of teaching, learning or research. ${ }^{1}$ We want to focus less on criticisms concerned with true or false representations, and consider instead how measurement practices actively modify the worlds they seek to measure (see Burrows, 2012; Redden, 2015). As studies of standardized testing have shown, learning environments cannot be subject to continual measurement without bringing into being new professional practices and anxieties responsive to metric cultures (see Redden \& Low, 2012). In some contexts, metrics used to determine teaching performance or research quality may even come to be treated as compliance-based games abstracted from pedagogical or intellectual purposes (see Anderson, 2006, p. 171). For this reason, in order to better understand forms of continuity and change in conceptions of $\mathrm{HDR}$, the following section examines the overlapping critiques levelled at

\footnotetext{
${ }^{1}$ See the Special Issue of the Journal of Education Policy on measurement (volume 30, number 3, 2015).
} 
measurement under the concept of neo-liberalism. In the final section of this article, we link various effects of the forms of measurement that attend contemporary PhD programmes in Australia.

\section{Four critiques of neo-liberalism in the university}

Contemporary scholarship on measurement in higher education has been profoundly shaped by the concept of neo-liberalism (e.g., Ball, 2015; Gill, 2016; Redden, 2015). According to David Harvey's influential approach, neo-liberalism holds that 'the social good will be maximized by maximizing the reach and frequency of market transactions, and it seeks to bring all human action into the domain of the market' $(2007$, p. 3). Harvey acknowledges that neo-liberal economic practices have developed 'unevenly' across the globe, and that state-sponsored neo-liberal policies have been 'partial', 'lopsided' and 'tentative' (p. 13). Nevertheless, despite the highly disparate phenomena now labelled as neo-liberal, Harvey suggests that the emergence of neo-liberal thought can be attributed to a broad historical situation: the crises of over-production in industrial and postindustrial economies that culminated in the early 1970s (pp. 11-14). This politicoeconomic explanation has faced numerous challenges, and Terry Flew (2014) notes that at least six distinct theories of neo-liberalism now circulate in sociology and economics. Among these, Michel Foucault's lectures on neo-liberal techniques of government have become highly influential. Across his broad oeuvre, Foucault traces the development of state-based institutions - schools, hospitals, psychiatric wards, the police force - that bring forth subjective dispositions through direct intervention into everyday habits, routines, desires, anxieties and so on (see Donzelot, 2008; Foucault, 2008). Rather than describing a re-articulation between capital and labour, Foucault's account of neo-liberalism focuses on its ethical prescriptions and epistemological presuppositions, including neo-liberal reconceptions of human behaviour, interest and justice. While Marxists and Foucauldians share an understanding that neo-liberalism seeks to marketize all manner of social relationships, the former tend to emphasize the erosion of collectivized labour rights and working conditions, while the latter take a greater interest in new forms of selfhood and ethical conduct that cut across class positions and socio-economic hierarchies. Such differences are reflected in the spectrum of criticisms weighed against neo-liberalism in higher education, which can be divided into four broad themes: commensuration, incentivization, corporatization and alienation. We will consider these criticisms in turn, before returning to the broader questions raised around metrics and HDR.

Firstly, there is a critique of commensuration, or the subsumption of diverse activities within a single quantitative calculation. Roger Burrows suggests that academic use-values were once properly distinguished from other value systems, such as aesthetic and commercial values, and that this distinction dissolved with the 'metricization' of the academy, which has 'flattened' culture through 'economic imperatives' (2012, p. 355). One example is the H-Index for academic citations, which combines 'the number of papers - as an aspect of quantity - and citations as a supposed aspect of quality, into a single number' (p. 361). The H-Index as a proxy indicator for research 'quality' or disciplinary 'impact' allows universities to compare publications from diverse disciplines as if they each contribute to a solid 
mass of something called knowledge. Structural analysis of the H-Index algorithm shows that it tacitly rewards publishing quantity over quality, partially as a result of its failure to signal the diversity of ways that intellectual labour can produce institutional or disciplinary value (see Costas \& Bordons, 2007).

Secondly, scholars have criticized incentivizing metrics, or those intended to promote workplace competition and constant self-improvement (Ball, 2015). From a Foucauldian perspective, neo-liberal governance through metrics requires remoulding subjects as competitive individuals, and therefore builds on cultural myths of self-determination and autonomy (see Stevenson, 2010). Rosalind Gill describes the calculative, neo-liberal university as 'an overheated competitive atmosphere in which acts of kindness, generosity and solidarity often seem to continue only in spite of, rather than because of, the governance of universities' (2016, pp. 46-47). While many new metrics are advertised as reflexive resources for monitoring and improving individual performances, competitive workplace environments inevitably position KPIs within a comparative frame: another's success becomes a possible sign of one's own failure. In the context of HDR programmes, fine grained differences between students can acquire a cumulative institutional force. For any given individual, slight under-performance relative to a cohort can mean decreased eligibility for awards, scholarships, teaching opportunities and so on.

Thirdly, scholars have criticized the corporatization of universities as a response to funding shortfalls in neo-liberal climes. Henry Giroux (2011) argues for the continuing need for universities to serve democratic interests within a nation as a whole, and has criticized efforts to price the value of education in micro-economic terms. The response from some institutions has been to make some pricing mechanisms more expansive - say, by including outputs not captured by conventional metrics, such as public impact and engagement. But for humanities programmes, some scholars have advanced broader arguments for the value contained in producing the 'personnel necessary for maintaining certain cultural and ethical levels in the population at large' (Hunter, 1989, p. 446). From this perspective, HDR programmes should not be evaluated through post-graduation employment rates or per capita research outputs, but through a more holistic analysis of the wider social benefits gained from the maintenance of collective understanding around culture, ethics, social conduct and so on. As lan Hunter has argued, there are risks in romanticizing disinterested learning, rather than identifying specific spheres - policy development, secondary education, public health - to which humanities graduates may make significant contributions (pp. 446-447). Nevertheless, the marketization of higher education does frequently punish those programmes that cannot point towards tangible vocational outcomes, and in Marxist terms, prioritizes the interests of capital investment over the quality of living for those who labour.

Finally, technologies of quantification have been criticized for their alienating effects. The experience of being measured can produce stress, exhaustion and frustration, even when no direct penalty is attached to outcomes (see Thompson \& Harbaugh, 2013). Metric cultures alienate academics from their own intellectual 
labour by producing an 'endlessly self-monitoring, planning, prioritising "responsibilised" subject' (Gill \& Pratt, 2008, p. 4). Stephen Ball $(2015$, p. 259) describes 'neoliberal affects' in terms of 'ontological insecurity' involving 'both a loss of a sense of meaning in what we do and of what is important in what we do'. Measurement practices can also transform social relationships within institutions, insofar as metrics come to function as impersonal and bureaucratic technologies. Burrows $(2012$, p. 363) argues that a regime of trust has shifted to a regime of accountability, and describes favourably an earlier era where 'collegiate discussion, the occasional argument and a few rough calculations by someone in authority was normally all that was involved in working out "who did what"'. The neoliberalization of the academy shifts agency away from communities of practitioners towards professional managers, often working at some considerable distance from classroom spaces or research projects. Sarah Ahmed (2012, p. 117) argues that the managerial goal of achieving measurable diversity 'outputs' can often supersede any consideration of the hierarchical social structures that keep racism, sexism and other forms of exclusion in place. Numbers can therefore come to 'stand in' or substitute for the absence of concrete social and political transformations.

These four critiques foreground social values and relationships within universities that cannot easily be measured, and that may be threatened by metric cultures. Commensuration threatens the singularity of ideas and disciplines; competitive incentivization threatens workplace solidarity; corporatization threatens the social benefits attending humanities education; and metric cultures alienate individuals from their own intellectual labour and from institutional decision-making. In each instance, 'strong theories' of neo-liberalism have indicted metricization as a harm to be eradicated, and in several of the works considered so far - most notably, Gill (2016), Burrows (2012) and Giroux (2011) - neo-liberalism becomes the primary battle-ground over which a range of institutional skirmishes take place. For scholars interested in doctoral education, the corresponding question could become: how can we defend the PhD from neo-liberalism, or from neo-liberal techniques of measurement?

We are broadly sympathetic to the critiques of commensuration, incentivization, corporatization and alienation. However, these critiques raise a central sociological problem: critiques of neo-liberalism in higher education are largely devoid of neoliberals. Neo-liberalism is understood as something that happens to people in institutions rather than something that happens through people in institutions. As indicated above, this tension may be partially reconciled by accounts of 'subject formation', wherein institutional forces are understood to compose individual dispositions through particular ways of being and doing (see Foucault, 1977). Universities are not necessarily overpopulated by individuals committed to neoliberalism ('neo-liberals'), but they do mould individual habits and orientations to be more compliant with the marketized turbulences of academic life. However, while certain situations bring forth dispositions that conform to an economic rationality, this only happens to a certain degree. Strong theories of neo-liberalism need to be coupled with what Sedgwick - again, following Tomkins - calls 'weak' theories (2003, pp. 134-135). Strong theories begin with a universalizing ideology that is then addressed according to its own universalizing register: in all times and 
all places, is neoliberalism good or bad? By contrast, a weak theory rejects universals and compiles its account of neo-liberalism by way of disparate and heterogeneous practices. These practices may have been captured by institutions shaped by neo-liberalism, but they do not necessarily originate with them. Weak theories might distinguish between measurement as an effect of latent causes (neo-liberalism, capitalism, corporatization), and measurement as a practice that enters into the life-worlds of those charged with measuring others, even as they themselves are measured.

To understand neo-liberal measurement from the viewpoint of practices, we want to distinguish between what Dutch philosopher Baruch Spinoza (1996) calls 'passive affects' and 'active affects'. Institutional practices imposed from the outside can be experienced as passive affects, because we are affected by them without having any recourse to affect these practices in turn. The experience of being measured through KPIs, for example, makes the individual passive in relation to the metrics used. For Spinoza, passive affects may be transformed into active affects when the self is experienced as a cause. Critiques of neo-liberalism focus on the passive affects of being measured, and promote forms of resistance that may be understood as active critique. In this way, the agency of individuals in neo-liberal settings is defined in positive, humanistic terms - the individual seeks to protect personal values and well-being against neo-liberal incursions. However, for neoliberal metrics to become effective, individuals must be sensitized to market (or market-like) signals (see Foucault, 2008, p. 269). In their capacities as tutors, coordinators and higher degree supervisors, academics are entrusted with the task of sensitizing others to various grades, quantities and rankings. Individuals' latent capacities to measure, evaluate, judge, advocate, deliberate and critique are constantly mobilized by techniques of neo-liberal government. As a research supervisor, the academic conveys ideas about appropriate rates of progress, journal rankings, the relative merits of various projects and so on. The experience of being measured implicitly involves training to become one who measures and who can train others to be measured. Certain scholars may even regard themselves with disdain as active causes of neo-liberal affects. Academics do not critique neoliberalism from an external vantage point, but rather from the situation of one whose competencies actively contribute to the markets they may seek to resist. This situation conforms to aspects of Marx's conception of alienation from the commodity form. Academic researchers as individuals contribute to a world of objects that disempower academics as a collective, insofar as present benchmarks for research performance are based on the 'dead' labour of past research (see Marx, 1974, pp. 61-63). But the situation also has immediately social and subjective elements. In HDR spaces, academics are charged with teaching others to inhabit the neo-liberal academy and its metric cultures. Furthermore, such obligations may even be met with enthusiasm. Pressures to conform to metric cultures may feel compelling because individuals are already compelled by other commitments. These may involve a love of reading and writing, a sense of fulfilment in the classroom, a pleasure in mentoring future academics, a desire for social status or simply the habitual comforts of working in a familiar and supportive social environment. Here, we follow John Clarke's argument that '[whether] we treat neoliberalism from the standpoint of capitalist regimes of accumulation, or as a version 
of liberal governmentality, most of its political work involves practices of de- and re-articulation: reorganizing principles, policies, practices, and discourses into new configurations, assemblages, or constellations.' (2008, pp. 138-139) The desire to participate in university life and to have stable employment is not exclusively a neoliberal one, but such desires can be re-articulated within a neo-liberal context. What Spinoza might call the 'joyful' affects of being an academic are intermingled with, rather than merely opposed to, the various measurements that shape everyday institutional labour.

In the following section, we focus directly on HDR in Australian universities. HDR, and in particular the PhD, provides an important interface between two polarized tendencies within contemporary higher education: the collective desire to develop original research that furthers disciplinary knowledge, and the pressure to produce measurable outputs that make HDR programmes sustainable within a neo-liberal organizational context.

\section{HDR in Australian universities}

Massification, marketization and internationalization have underpinned significant changes in Western universities since the Second World War, and in Australia, significantly intensified in the 1980s (Barcan, 2013, p. 6). In 1980, 330,000 students were enrolled in Australian higher education, increasing to 1,221,008 by 2011 (Barcan, 2013, p. 32). The Group of Eight (2013) reported in 2013 that between 2000 and 2010, doctoral enrolments at Australian universities grew from 27,966 to 47,066 (68\%), and PhD completions increased from 3793 to 6053 per year. For Ruth Barcan, 'The creation of a large and variegated [Post-War tertiary] sector...put in place all the elements required for a more prominent role for the market: diversity, competition and an emphasis on consumer rights' $(2013$, p. 39). The demand that universities be accountable for public funding has intensified pressures on HDR Masters and doctoral completions, which are now understood primarily as institutional 'outputs'. Students are increasingly held accountable for timely completion through regular reporting, review panels, work-in-progress seminars and informal contracts. Correspondingly, the tendency towards what Pam Green and Robin Usher (2003, p. 44) call 'fast' supervision is formalized through mandatory training modules and university registers, with a focus on the frequency of meetings, length of time for feedback on work, and progress planning and annual reviews. Christine Halse and Peter Bansel characterize the outcomes-oriented model of supervision as 'reductive' because it 'construes doctoral students, supervisors, and supervision as [simply] an aggregation of identifiable, universal factors that can be reduced to quantifiable metrics' (Halse \& Bansel, 2012, p. 381). There may be three distinct benefits to embedded measurement practices within HDR candidatures.

Firstly, they can help to overcome the still widespread discourse on intelligence and giftedness. When one speaks of a 'good' project, one simply refers to the potential for 'good' future outcomes for the student. This pragmatic attitude places accreditation hurdles within their proper institutional context, rather than allowing $\mathrm{PhD}$ and Master's projects to become inflated symbols for intellectual genius. Secondly, metrics in HDR spaces can provide important forms of leverage when 
seeking to secure better provisions around research training and student support (Halse \& Bansel, 2012, p. 381). With a touch of irony, the measurement of learning spaces can be identified both with increasing pressures on performance and outputs, and with the development of more holistic measurements for students' experiences of anxiety, depression and so on. Thirdly, rates of non-completion are significantly reduced through continuous measurement, which is often used to identify 'at risk' projects. The event of submission is stretched backwards across the entire candidature, so that for the contemporary HDR candidate, preparedness to submit becomes an active variable from the first day of enrolment. Correspondingly, students become sensitized to a range of positive and negative indicators about their activities, from coursework to annual reviews, to peer reviews and teaching evaluations, to publication track records and the $\mathrm{H}$-Index. In this context, an 'at risk' student becomes one less sensitized to institutional indicators than their peers, or who is receiving indicators from a narrower range of sources.

However, describing measurement in this way atomizes the individual, and obscures the social processes that endow institutional signs with social meanings. Postgraduate enculturation, like academic communities in general, is organized by gossip, as a source of useful information, as a means of consolidating social relationships and as tacit training in the verification of competing truth-claims (Grealy, 2016; Grealy \& Laurie, in press). PhD candidates will gossip about measurements ranging from progress and annual reviews, journal article acceptances and rejections, views on an online profile, appropriate numbers of publications or teaching appointments on an academic $\mathrm{CV}$, and the ranking of institutions. Such conversations are one means by which students and their supervisors come to learn which metrics have serious consequences, and which merely operate as organizational shorthands, even if constantly called into question or debunked. The metrics that matter are also likely to change across the course of a student's candidature, from revised disciplinary definitions of 'research excellence' to national funding changes, such as the Australian federal government's proposal that university funding be partially delinked from research output (see Department of Education and Training, 2016). In this context, future research on measurement in HDR programmes might consider the social worlds developed by students in relation to institutional expectations. For the remainder of this discussion, however, we want to consider some of the issues raised by measurement in relation to doctoral education tout court. The proliferation of measurement practices within doctoral programmes has met with resistance. Andrew Riemer is often quoted for recollections of an era when academics regarded students with disdain, and where interventionist supervision 'would have seemed a breach of good manners - or intolerable intrusion' (quoted in Cribb \& Gewirtz, 2006, p. 225; see also Barcan, 2013, p. 14). Such nostalgic criticisms can be countered by examples of students who suffer from a lack of institutional support or coherent professionalization, and who become isolated and discontinue their study. This is not about framing students as 'consumers', but about recognizing inherent organizational flaws to any trust-based regime. More compelling criticisms can be made of the unanticipated impacts of measurement practices on research cultures. We noted above that in selection processes for HDR 
candidates in Australian universities, it is assumed that students will have already produced signals of excellence through performance in undergraduate and Honours programmes. This early screening of students may produce unexpected harms. A survey of scientists in Britain's Royal Society, for example, showed that 46 per cent had not received a 'first' as undergraduates (see Grove, 2016). There may be potentially adverse effects of removing from the postgraduate pool students who have not reached 'peak' performance as undergraduates. Furthermore, once a HDR programme has commenced, continuous measurement may reward projects that produce immediate results in order to satisfy institutional hurdles in early candidature. Whether enforced directly by a supervisor, or indirectly normalized through a wider institutional environment, highly measured environments provide incentives towards conservatism in topics and research design.

These issues are not unique to doctoral programmes, and many have already been raised by the four critiques of neo-liberalism surveyed above. Nevertheless, doctoral research projects do have singular qualities. Singularities cannot be broken into smaller component pieces without fundamentally changing their character. For example, the three-year Doctor of Philosophy is not a research activity that merely combines six semesters into a single accreditation hurdle. For many students, the desire to complete a PhD, and to adopt an identity as a PhD student, is not experienced merely as an aggregate of networks and outputs. Candidates recognize an important and profound difference between completing and not completing, and this difference is never equivalent to the 'amount' learnt. The doctorate therefore has a special kind of temporality, or what French philosopher Henri Bergson might call a singular duration (1920, p. 238). Many of the benefits frequently linked to $\mathrm{PhD}$ candidature require a minimal passing of time: disciplinary mastery, professional know-how, experience as a teacher, the building of social and institutional relationships and so on. Doctoral candidates are therefore not encouraged to shop around for supervisors from semester to semester, and a certain modicum of instability and confusion is still tolerated in doctoral programmes for much longer than most other tertiary programmes. Most importantly, the extended duration of doctoral education provides a space for failure. For some students, the traces of learning are strewn across a series of disappointments, misfirings and desertions. As queer theorist J. Jack Halberstam (2011) notes, the most ambitious and transformative collective projects may be experienced by individual agents as failures. Hazardous leaps towards genuinely new research may easily be disregarded as simply bad research, even by researchers themselves. Over time, failures may be recuperated as germinal moments in successful intellectual or political endeavours, but this 'over time' provides no guarantees. Society does not transform itself by realizing the goals that it sets for itself, but by creating spaces where new goals can emerge, however much they might violate existing utilitarian calculations. Failing and abandoned research projects can do important transformative work in testing the capacities and limits of a discipline. However, recognizing the productive dimensions of failure should not amount to a reckless disregard of pastoral care. Intellectual and professional failure can be highly damaging to students, and the well-being of PhD candidates is certainly linked to the personal perception of producing 'successful', 'valuable' and 'important' work. But these terms acquire an entirely different meaning - and, we 
want to suggest, a much less desirable meaning - in learning environments where failure is perceived in purely negative terms. A doctoral candidate should be able to make decisions in a context where failure is understood to be a productive part of disciplinary growth, and not a sign of intellectual weakness.

\section{Conclusion}

It is difficult to write about the immeasurable worth of education without a certain degree of implicit elitism. The presence of instrumentalization, professionalization and fiscal accountability does not always mean a moral failing on the part of universities. Critiques of neo-liberalism have to recognize that collective attachments to numbers may reflect real tensions in the shifting purposes of higher education. While numbers do not necessarily produce well-formed ideas about education, there are many ideas about education that can only be promoted through the institutional force of measurement practices. Furthermore, given that neo-liberal economic thought is regularly criticized for being monolithic and reductive, it is important that 'anti-neo-liberalism' does not become equally monolithic. The institutional and political projects that conflict with neo-liberalism may themselves be extremely diverse. For this reason, scholarship on higher education is not always served well by the adoption of 'pro' or 'anti' stances in relation to metrics. The issue concerns the manner by which numbers come to take effect in organizational settings, and the extent to which effective numbers sediment as unassailable social facts. It is one thing to say that a given economic structure requires the minimal diffusion of a particular practical rationality. It is another thing to infer that a structure optimizes this rationality, as if each individual must repeat actions in the same way, to the same degree and to the same effect. We must therefore separate the concept of neo-liberal subjectivity, a position that may not necessarily be occupied by any single individual, from the dispositions adopted by those entrusted to comply with and administer neo-liberal metrics.

This article has made no firm prescriptions concerning the desirability of measurement practices per se. The elongated data chain of measurements in education significantly exceeds the purview of any particular individual programme, school or university, and certain metrics perceived as socially deleterious (e.g., quantified research outputs) often coexist with metrics intended to produce better social outcomes (e.g., rates for participation along lines of gender, ethnicity, ability and so on). There is an inescapable gap between the numbers that carry instrumental value in the phenomenological life-worlds of practitioners, and numbers that seem to float away into the bureaucratic abyss, only to return - sometimes without warning - in annual reports, strategic planning days or grant application processes. Whatever their manner of arrival, the forces that allow new metrics to be instituted cannot be changed simply through denunciations of neo-liberalism. The introduction of bad numbers cannot be countered by an argument for no numbers unless strong alternative visions for organizational processes or educational purposes are offered. In this context, we have made some initial steps towards an engagement with the specific constraints that attend local measurements, and argued for a thicker account of organizational practices than global commentaries on the neo-liberal university would currently allow. 


\section{References}

Ahmed, S. (2012). On being included: Racism and diversity in institutional life. Durham, NC: Duke University Press.

Anderson, G. (2006). Assuring quality/resisting quality assurance: Academics' responses to 'quality' in some Australian universities. Quality in Higher Education, 12(2), 161-173.

Ball, S. J. (2015). Living the neo-liberal university. European Journal of Education, 50(3), 258-261.

Barcan, R. (2013). Academic life and labour in the new university: Hope and other choices. London: Ashgate.

Bergson, H. (1920). Creative evolution. (A. Mitchell, Trans.). London: Macmillan.

Bowman, N. A., \& Bastedo, M. N. (2011). Anchoring effects in world university rankings: Exploring biases in reputation scores. Higher Education, 61(4), 431-444.

Burrows, R. (2012). Living with the H-index? Metric assemblages in the contemporary academy. The Sociological Review, 60(2), 355-372.

Clarke, J. (2008). Living with/in and without neo-liberalism. Focaal, 51, 135-147.

Costas, R., \& Bordons, M. (2007). The H-index: Advantages, limitations and its relation with other bibliometric indicators at the micro level. Journal of Informetrics, 1(3), 193-203.

Cribb, A., \& Gewirtz, S. (2006). Doctoral student supervision in a managerial climate. International Studies in Sociology of Education, 16(3), 223-236.

The Department of Education and Training. (2016). New research funding arrangements for universities. The Australian Government. Retrieved from http://www.innovation.gov.au/page/newresearch-funding-arrangementsuniversities

Donzelot, J. (2008). Michel Foucault and liberal intelligence. Economy and Society, 37(1), 115-134.

Flew, T. (2014). Six theories of neoliberalism. Thesis Eleven, 122(1), 49-71.

Foucault, M. (1977). Discipline and punish: The birth of the prison. London: Penguin.

Foucault, M. (2008). The birth of biopolitics: Lectures at the Collège de France, 1978-1979. (G.

Burchell, Trans.). Basingstoke: Palgrave Macmillan.

Gill, R. (2016). Breaking the silence: The hidden injuries of neo-liberal academia. Feministische Studien, 34(1), 39-55.

Gill, R., \& Pratt, A. C. (2008). In the social factory? Immaterial labour, precariousness and cultural work. Theory Culture Society, 25(7/8), 1-30.

Giroux, H. A. (2011). Neoliberal politics as failed sociality: Youth and the crisis of higher education. Logos: A Journal of Modern Society \& Culture, 10(2), n.p.

Grealy, L. (2016). Cliché, gossip, and anecdote as supervision training. The Review of Education, Pedagogy, and Cultural Studies, 38(4), 341-359.

Grealy, L., \& Laurie, T. (in press). The ethics of postgraduate supervision: A view from cultural studies. In J. Aksikas, S. Johnson, \& D. Hedrick (Eds.), Cultural 
studies in the classroom and beyond: Critical pedagogies and classroom strategies.

Green, P., \& Usher, R. (2003). Fast supervision: Changing supervisory practice in changing times. Studies in Continuing Education, 25(1), 37-50.

Group of Eight. (2013, March). The changing PhD. Discussion paper.

Grove, J. (2016, February 16). Many top scientists did not have a first, says study. The Times Higher Education Supplement.

Halberstam, J. J. (2011). The queer art of failure. Durham, NC: Duke University Press.

Halse, C., \& Bansel, P. (2012). The learning alliance: Ethics in doctoral supervision. Oxford Review of Education, 38(4), 377-392.

Harvey, D. (2007). A brief history of neoliberalism. Oxford: Oxford University Press.

Hunter, I. (1989). Accounting for the humanities. Meanjin, 48(3), 438-448.

Kamuf, P. (2007). Accounterability. Textual Practice, 21(2), 251-266.

Marx, K. (1974). Economic and philosophic manuscripts of 1844. Moscow: Progress.

Mayhew, M. (2014). Marginal inquiries. In A. Wardrop \& D. Withers (Eds.), The para-academic handbook: A toolkit for making, learning, creating, acting (pp. 263-290). Bristol: HammerOn Press.

Redden, G. (2008). From RAE to ERA: Research evaluation at work in the corporate university. Australian Humanities Review, 45, n.p.

Redden, G. (2015). Culture, value and commensuration: The knowledge politics of indicators. In L.

MacDowall, M. Badham, E. Blomkamp, \& K. Dunphy (Eds.), Making culture count: The politics of cultural measurement (pp. 27-41). London: Palgrave Macmillan.

Redden, G., \& Low, R. (2012). My school, education, and cultures of rating and ranking. Review of Education, Pedagogy, and Cultural Studies, 34(1-2), 3548.

RMIT University. (2011). 2011 scholarships and RTS ranking: Model to determine merit-based selection. Retrieved from http://mams.rmit.edu.au/hflhfepzk96I1.pdf

Roberts-Holmes, G. (2015). The 'datafication' of early years pedagogy: 'If the teaching is good, the data should be good and if there's bad teaching, there is bad data'. Journal of Education Policy, 30 (3), 302-315.

Sedgwick, E. K. (2003). Touching feeling: Affect, pedagogy, performativity. Durham, NC: Duke University Press.

Shachter, R. D. (1988). Probabilistic inference and influence diagrams. Operations Research, 36(4), 589-604.

Shahjahan, R. A. (2015). Being 'lazy' and slowing down: Toward decolonizing time, our body, and pedagogy. Educational Philosophy and Theory, 47(5), 488501.

Spinoza, B. de. (1996). Ethics. (E. Curley, Trans.). London: Penguin.

Stevenson, N. (2010). Education, neoliberalism and cultural citizenship: Living in ' $X$ factor' Britain. European Journal of Cultural Studies, 13(3), 341-358. 
Thompson, G., \& Harbaugh, A. G. (2013). A preliminary analysis of teacher perceptions of the effects of NAPLAN on pedagogy and curriculum. The Australian Education Researcher, 40(3), 299-314. 